\title{
Heat Recovery for next Generation of Hybrid Vehicles: Simulation and Design of a Rankine Cycle System
}

\author{
Alexandre Duparchy ${ }^{1}$, Pierre Leduc, Guillaume Bourhis, Cyprien Ternel \\ ${ }^{I}$ IFP, 1-4 avenue de Bois Préau, 92852 Rueil-Malmaison, alexandre.duparchy@ifp.fr
}

\begin{abstract}
Improvements of vehicle effectiveness thanks to hybridisation are limited by the engine efficiency. In this way, the use of additional energy converters pave the way to a next generation of hybrid vehicles.

After taking stock of the main sources of recoverable energy of a IC engine, this paper focuses on the Rankine cycle solution. This parametric study relies on a dedicated 0D/1D simulation tool to emphasize the effect of design and operating parameters on heat recovery potential and limitations. So, interactions between working fluid properties, pressure level in boiler and condenser, flow rate, component arrangement and engine operating conditions are discussed.
\end{abstract}

Keywords: energy recovery, passenger car, simulation

\section{Introduction and motivations}

Hybridisation significantly improves the energy efficiency of vehicles. The thermal engine can be managed intelligently by adding an electrical energy source and possibly using a dedicated transmission. Through these modifications, it is possible to dissociate the engine torque from the torque demand at the wheel and choose the operating engine speed requiring the least energy to provide the requested power. By separating the instantaneous torque requirement and the engine operating point, therefore, hybridisation allows the engine to run on its optimum efficiency zone. Efficiency is further improved by implementing regenerative braking systems.

The energy efficiency currently attained by these vehicles represents a considerable step forward. It is limited, however, by the maximum efficiency of the internal combustion engine and, consequently, cannot exceed $35 \%$ to $40 \%$. As a result, analysing the recovery of heat energies lost in combustion engines opens the way to new opportunities for improving fuel consumption.

The simulation studies discussed in this document were conducted during construction of a prototype for recovery of lost energies via a bottoming Rankine cycle on engine test bench. They follow on from the balances produced from studies conducted by Bourhis [1] and include some of the technological choices associated with development of the prototype. The recoverable energy balances will be used to propose an initial configuration which will act as a basis to perform a certain number of simulations. The aim of these simulations, based on a tool developed at IFP, is firstly to understand the influence of the Rankine bottoming cycle parameters and propose recommendations to optimise the energy recovered. Secondly, these rules are used to compare various configurations of the Rankine system without systematically resorting to the use of multiparametric variations. The setpoint values may also serve as a basis for a future control-command system. 


\section{Context}

Energies lost in engines can be recovered both on conventional (passenger car, heavy duty) and hybrid vehicles. The specifications of the prototype tested at IFP were intended for application on a hybrid vehicle, since this type of vehicle offers several advantages:

- Operation of the thermal engine is less transient

- There is already a means of storing the energy produced by the recovery system.

For reasons of correspondence between the power available in the energies lost and the vehicle requirements, it is worthwhile having a storage means, even despite its energy cost. Typically therefore, the characteristics (power and torque) of the engine chosen for this parametric study are those of an hybrid passenger car like Toyota Prius or Honda Insight (Table 1).

Table 1: Engine characteristics

\begin{tabular}{|l|c|}
\hline Air supply & naturally aspirated \\
\hline Max. torque & $95 \mathrm{~N} . \mathrm{m}$ \\
\hline Max. power & $54.7 \mathrm{~kW}$ \\
\hline Min. BSFC & $235 \mathrm{~g} /(\mathrm{kW} . \mathrm{h})$ \\
\hline
\end{tabular}

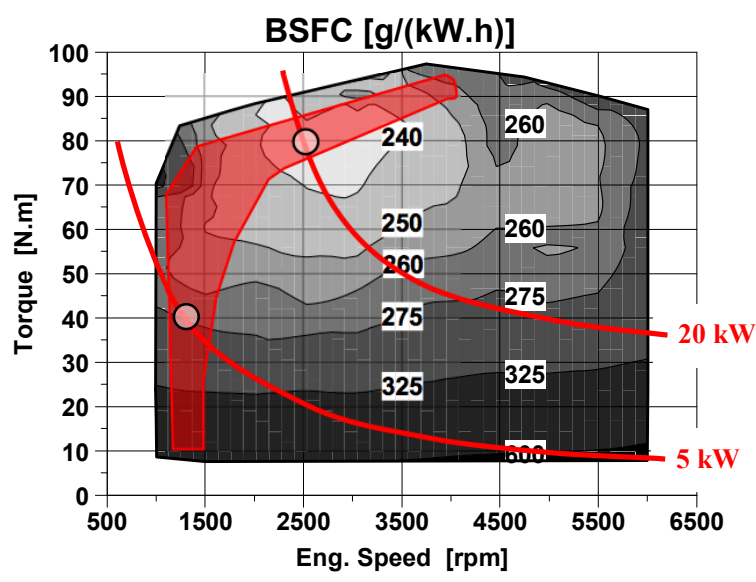

Figure 1: Operating zone

Similarly, the operating points chosen for design and simulations are those of a vehicle of the same type during stabilised runs at $70 \mathrm{~km} / \mathrm{h}$ and $120 \mathrm{~km} / \mathrm{h}$. These points correspond respectively to a rolling resistance of $5 \mathrm{~kW}$ and $20 \mathrm{~kW}$. Considering the energy management strategies of a power-split hybrid (see [2]), the operating points are those shown in Table 2 and on the engine cartography of Figure 1.
Table 2: operating points chosen for design and simulations

\begin{tabular}{|l|c|c|}
\hline & op\#1 & op\#2 \\
\hline situation & stab $70 \mathrm{~km} / \mathrm{h}$ & stab $120 \mathrm{~km} / \mathrm{h}$ \\
\hline Eng. Speed & $1250 \mathrm{rpm}$ & $2500 \mathrm{rpm}$ \\
\hline BMEP & $5 \mathrm{bar}$ & $10 \mathrm{bar}$ \\
\hline BSFC & $275 \mathrm{~g} /(\mathrm{kW} . \mathrm{h})$ & $237 \mathrm{~g} /(\mathrm{kW} . \mathrm{h})$ \\
\hline Pexh & $1 \mathrm{bars}$ & $1 \mathrm{bars}$ \\
\hline Texh & $550{ }^{\circ} \mathrm{C}$ & $790^{\circ} \mathrm{C}$ \\
\hline Exh gas flow & $6.06 \mathrm{E}-03 \mathrm{~kg} / \mathrm{s}$ & $2.12 \mathrm{E}-02 \mathrm{~kg} / \mathrm{s}$ \\
\hline Pwater & $1.78 \mathrm{bars}$ & $1.78 \mathrm{bars}$ \\
\hline Twater in & $85.6^{\circ} \mathrm{C}$ & $84.4^{\circ} \mathrm{C}$ \\
\hline Twater out & $88.3^{\circ} \mathrm{C}$ & $87.7^{\circ} \mathrm{C}$ \\
\hline Water flow & $0.562 \mathrm{~kg} / \mathrm{s}$ & $1.126 \mathrm{~kg} / \mathrm{s}$ \\
\hline
\end{tabular}

\subsection{Recovery system}

Amongst the various systems [3] available to convert heat into useful energy on board the vehicle, we decided to study the Rankine bottoming cycle. These systems, already developed for heavy duty vehicles [4] and sea transport [5], are currently being studied for applications on passenger car (see [6] and [7]).

\subsubsection{The Rankine bottoming cycle}

The Rankine bottoming cycle is a closed circuit dithermal thermodynamic cycle in which the working fluid changes phase (liquid/vapour). Ideally, it can be broken down into the following four steps:

- $1 \rightarrow 2$ : The fluid, in liquid state, is compressed isentropically.

- $2 \rightarrow 3$ : The fluid, in liquid state, is heated and vaporised in contact with the hot source.

- $3 \rightarrow 4$ : The vapour is expanded isentropically in an expander.

- $\quad 4 \rightarrow 1$ : On leaving the turbine, the fluid is cooled and condensed in contact with the cold source.

Figure 2 shows a diagrammatic representation of a Rankine system in its simplest version. 


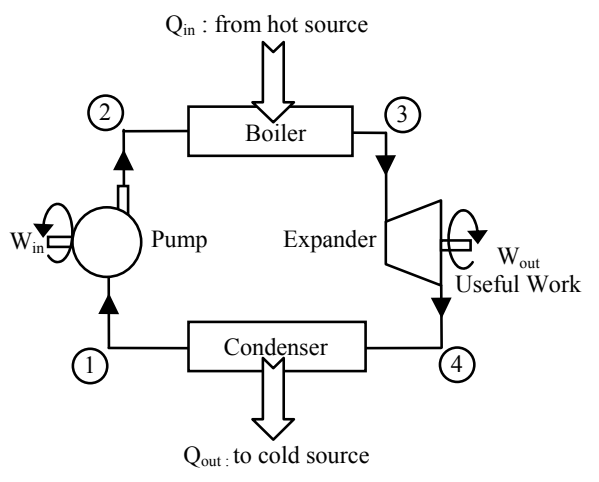

Figure 2: Rankine system

It is convenient to use the T-S diagram to represent the thermodynamic states of the fluid during the cycle, since it allows us to make a comparison with the Carnot cycle. For example, Figure 3 compares the theoretical cycle and the "real" cycle. The real cycle takes account of the fact that the heat exchanges with the hot and cold sources require a temperature difference and that it is impossible to make isentropic transformations.

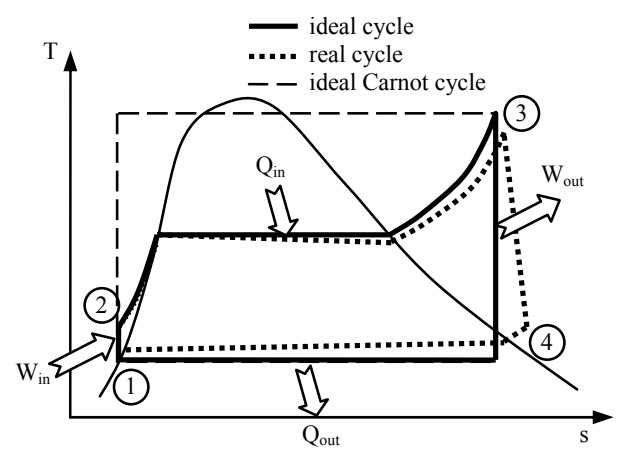

Figure 3: Representation of the cycle as a T-S diagram

\subsubsection{Definitions}

In the remainder of the document, we will use the definitions given below.

The energy transfer efficiency is used to qualify the heat exchange : it represents the energy transmitted to the working fluid compared with the energy contained in the exhaust gases:

$\eta_{t}=Q_{i n} / E_{e x h}$

The thermodynamic efficiency or cycle efficiency is used to qualify the production of work : it represents the work recovered compared with the energy transmitted to the fluid:

$\eta_{c}=\left(W_{\text {out }}-W_{\text {in }}\right) / Q_{\text {in }}$

The global efficiency is the product of the two : the aim is to qualify the ability of the system to recover energy and convert it into work. This is the efficiency we are trying to maximise:

$\eta=\left(W_{\text {out }}-W_{\text {in }}\right) / E_{\text {exh }}=\eta_{t} \cdot \eta_{c}$

The Carnot cycle, represented by the rectangle on Figure 3, gives the maximum theoretical thermodynamic efficiency of a dithermal cycle. We must remember that, firstly, its representation in the T-S diagram is simple and, secondly, it can be used to locate the imperfections of the Rankine cycle.

In all cases, the work supplied by one of the cycles shown on Figure 3 is proportional to the area marked out.

\subsubsection{Control parameters}

Engineers can control the cycle and optimise the energy recovered according to the engine operating conditions in various ways. Three parameters can be set :

- The heat exchange fluid flow rate $Q_{f}$

- The pressure in the high pressure ("hp") part of the circuit $P_{h p}$

- The pressure in the low pressure ("lp") part of the circuit $P_{l p}$

\section{Exergy and recoverable work balances}

Before recovering the energies lost in the thermal engine, we must first identify the main recovery sources. These sources are located in the main flows of lost energies, i.e. the exhaust gases and the cooling circuit [8]. The energy is in the form of heat. However, this energy can only be used to improve the engine efficiency if it can be used to perform work. To remain relevant, therefore, the lost energy balance must indicate the fraction that can be converted into work. This analysis involves the notion of exergy. 


\subsection{Exergy}

\subsubsection{Definition}

The notion of exergy, derived from the second law of thermodynamics, represents the work that can be extracted when a thermodynamic system $(\Sigma)$ is taken reversibly from its initial state (state 1) to equilibrium with its environment (state 0 ). We simply demonstrate that it is the maximum recoverable work, irrespective of the transformation taking $\Sigma$ from 1 to 0 . Exergy is not a state function of the system but a combined quantity which depends on the system and its environment. Extensively detailed in [9] and [10], with a non-reactive open system, exergy is defined by :

$$
E x=\left(H-H_{0}\right)-T_{0}\left(S-S_{0}\right)
$$

In equation (4), index 0 represents the state of the system at equilibrium with the reference environment. In particular, $T_{0}$ is the temperature of the environment. Using (4), we can write the exergy variation between states 1 and 2 of the same system in contact with an environment at temperature $T_{0}$ :

$$
\Delta E x_{1,2}=\left(H_{2}-H_{1}\right)-T_{0}\left(S_{2}-S_{1}\right)
$$

Described differently, exergy can be used to identify, out of the total energy contained in a system, in all its possible forms (heat, pressure, chemical, etc.), the maximum fraction that can be converted into work.

\subsubsection{Properties}

It is important to note that exergy, which involves entropy, is not conserved. The transfer of energy (heat, work) from a system $\Sigma$ to a system $\Gamma$ always takes place with a transfer of exergy meeting two constraints:

- The exergy variation of $\Sigma$ is less than or equal to the energy transferred.

- In absolute value, the exergy variation of $\Sigma$ during the transfer is greater than or equal to that of $\Gamma$. There is necessarily destruction of exergy caused by irreversibilities.

In particular the heat exchanges are major sources of exergy destruction The greater the temperature difference between the two systems, the greater the exergy destruction ([1], [9] and [10]).

For a non-reactive fluid subjected to an isobaric heat input, the lower its weight the greater the exergy variation. In other words, for a given quantity of heat transmitted, the lower the quantity of receiver fluid, the greater the amount of recoverable work.

\subsection{Energy and exergy balances}

This paragraph draws up a balance of the energy available and the recoverable work (exergy) for the two main sources of energy loss targeted by the use of a Rankine bottoming cycle : the exhaust gases and the cooling water circuit, since they represent two large energy flows [8] which are accessible since the heat flow is channelled.

These balances complement the studies discussed in [1]. They concern the complete map of the engine and are produced on the basis of the tests carried out engine bench at IFP and on NIST ${ }^{1}$ data using REFPROP software.

\subsubsection{Energy balances}

The energy flow at the exhaust, illustrated on Figure 4, includes only the thermal part of the energy transported. It is calculated from the pressure and temperature measurements at the outlet of the 3-way catalyst since, for catalyst efficiency and light-off reasons, this is the best place to implement a recovery system. The fluid considered is a theoretical mixture determined from the equivalence ratio measurement on the engine bench. It is a mixture of $\mathrm{N}_{2}, \mathrm{H}_{2} \mathrm{O}, \mathrm{CO}_{2}$, and possibly $\mathrm{CO}$ or $\mathrm{O}_{2}$ depending on the equivalence ratio measured. This mixture is used to determine the enthalpy of the gases output from the catalyser $h_{\text {exh }}^{\text {out } 3 W}$ and under ambient conditions $h_{\text {exh }}^{0}$. We therefore have:

$$
E_{e x h}=\dot{m}_{e x h}\left(h_{e x h}^{o u t ~} 3 W-h_{e x h}^{0}\right)
$$

\footnotetext{
${ }^{1}$ National Institute of Standards and Technology, U.S. Department of Commerce
} 


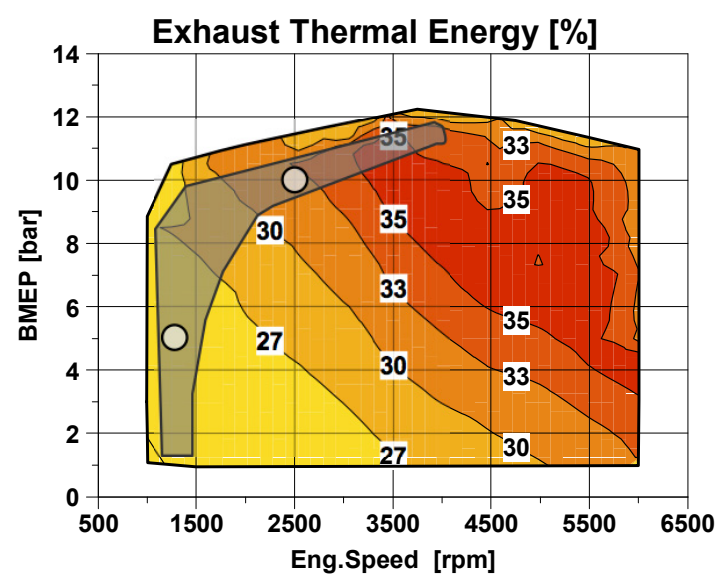

Figure 4: Proportion of the energy introduced dissipated as thermal energy in the exhaust (downstream from the catalyst)

The energy flow in the cooling water, shown on Figure 5, is determined from the water flow rate, circuit pressure measurement and temperature measurements at engine input and output. It therefore corresponds to the energy dissipated in the radiator.

$$
E_{w}=\dot{m}_{w}\left(h_{w}^{\text {out }}-h_{w}^{\text {in }}\right)
$$

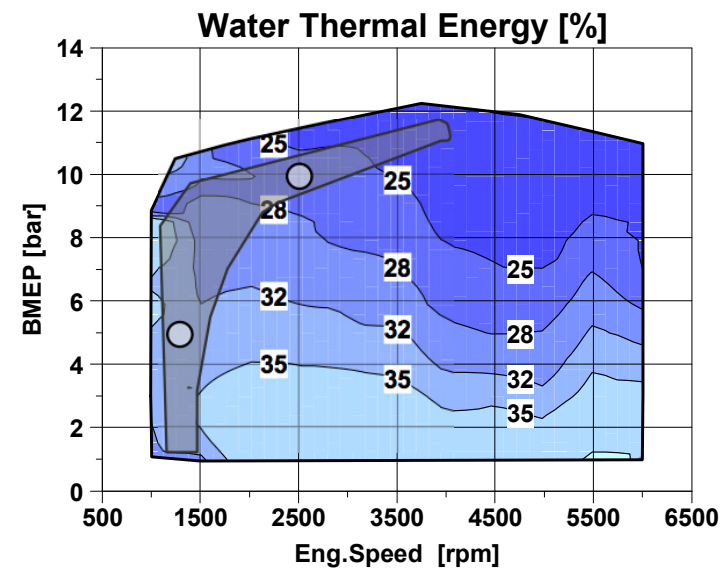

Figure 5: Proportion of the energy introduced dissipated as thermal energy in the cooling water

Comparison of Figure 4 and Figure 5 shows that the proportion of thermal energy lost at the exhaust is comparable with that dissipated in the cooling water, in particular on the operating points concerned by a hybrid vehicle.

\subsubsection{Exergy balances}

As with the energy balances (see 3.2.1), exergy is calculated from the results obtained on the test bench at IFP and the REFPROP thermodynamic data. The exergy contained in the exhaust gases is calculated according to formula (8), i.e. assuming a reversible transformation up to ambient conditions :

$$
\Delta E x_{e x h}=\dot{m}_{e x h}\left(h_{e x h}^{\text {out } 3 W}-h_{e x h}^{0}\right)-\dot{m}_{e x h} T_{0}\left(s_{\text {exh }}^{\text {out } 3 W}-s_{\text {exh }}^{0}\right)
$$

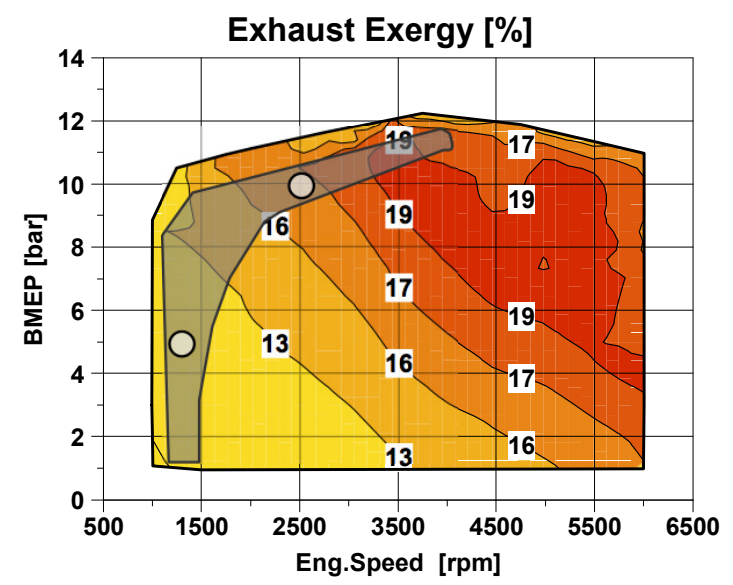

Figure 6: Quantity of energy recoverable as work in the exhaust gases (reduced to the LHV introduced)

The exergy contained in the cooling water is calculated according to formula (9). It corresponds to the maximum exergy that can be transmitted to a recovery system capable of absorbing the same power as the radiator.

$$
\Delta E x_{w}=\dot{m}_{w}\left(h_{w}^{\text {out }}-h_{w}^{\text {in }}\right)-\dot{m}_{w} T_{0}\left(s_{w}^{\text {out }}-s_{w}^{\text {in }}\right)
$$

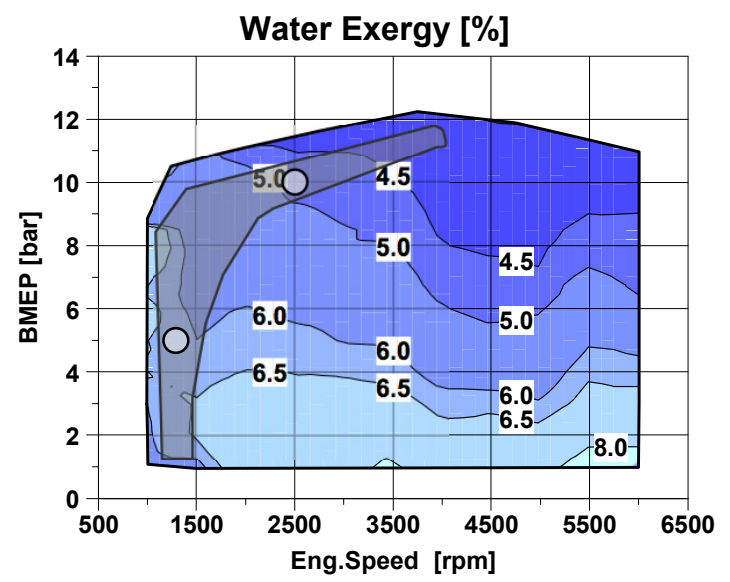

Figure 7: Quantity of energy recoverable as work in the engine cooling water

As already seen, from the energy point of view, these two sources are therefore roughly 
equivalent. Analysis in terms of exergy, however, indicates a much greater recovery potential at the exhaust. This is due to a large difference in the thermodynamic properties of the two fluids and also to the fact that the mass flow rate of the exhaust gases is between ten and one hundred times less than that of the cooling water. So that the irreversibility term $\dot{m}_{i} T_{0}\left(s_{i}^{\text {out }}-s_{i}^{\text {in }}\right)$ is much important in the case of water. For a comparable quantity of heat contained therefore, the impact in terms of exergy is much greater at the exhaust. The exhaust therefore represents the heat source offering the best potential for lost energy recovery. This heat source will be privileged during the simulations.

\section{Parametric study}

A first series of simulations was conducted to identify the impact of the three parameters $\left(Q_{f}\right.$, $P_{h p}$ and $P_{l p}$ ) on the energy recovered in the expander. We therefore decided to change the parameters on the two engine operating points described Table 2.

\subsection{Simulated configuration}

In this study, water was chosen as working fluid since the preliminary studies conducted at IFP demonstrated that it offered the best potential in terms of global efficiency of the cycle for application to the spark ignition engine (high exhaust gas temperature $>700{ }^{\circ} \mathrm{C}$ ). In addition, considering the exergy balances determined in paragraph 3.2, the simulated configuration consists in recovery the thermal energy of the exhaust gases (Figure 8).

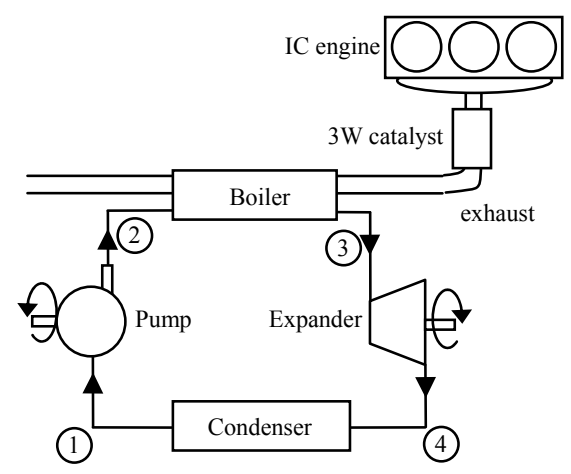

Figure 8: Diagram of layout at the exhaust

The boiler is installed downstream from the catalyst to avoid penalising light-off when cold start and benefit from the energy produced during pollutant conversion. Honda used the same setup to build its prototype [11]. In this configuration, the boiler was designed to achieve $90 \%$ efficiency under the operating conditions of the point at $20 \mathrm{~kW}$ (op\#2 see Table 2). A counter-flow boiler is used. The condenser was designed to dissipate $20 \mathrm{~kW}$ for steam at 1 bar and ambient temperature of $20^{\circ} \mathrm{C}$.

\subsection{Simulation tool}

The simulation tool produced to conduct this study implements the NIST database REFPROP. It can therefore be used to test the influence of numerous fluids and their mixtures. In addition, the composition of the exhaust gases can be taken into account.

0D (compressor/expander) and 1D (heat exchangers) models were used. It has not yet been calibrated on experimental tests and is probably not predictive regarding design of the heat exchangers. It is nevertheless capable of reproducing the trends and is powerful enough to study the influence of the Rankine bottoming cycle control parameters.

\subsubsection{Expander}

The expander is a key component of the Rankine bottoming cycle. The model used in this study is very simple, however, since the aim is to calculate expansion from the pressure conditions and isentropic efficiency data. Moreover, for all the simulations described here, this isentropic efficiency is set at $85 \%$ and corresponds to the optimum value that can be obtained with a piston machine.

A simplistic model was chosen for the expander since this component is highly dependent on the working fluid used and the pressure ranges considered. The behaviours of the various types of machine vary widely, however, and in order to simulate them a model would have to be encoded for each machine type. This is not the purpose of the tool used. It will be developed at a later stage using the AMESim simulation platform (see 6.2). The efficiency calculations of the future prototype on engine bench may also be used.

\subsubsection{Compressor model}

As for the expander, the compressor is simulated via limiting conditions and a compression isentropic efficiency of $85 \%$. Since this model is 
applied to compression of a liquid, it is far more reliable than with the expander.

\subsubsection{Heat exchanger models}

The heat exchanger models (boiler and condenser) are based on correlations from the literature ([12] and [13]). A one-dimensional simulation of an exchanger is used, with no longitudinal conduction through the material. The boiling phase, the thermal boundary layer determination phase and the flow mode transitions are shown however.

\subsection{Simulation results}

The results of these first simulations reveal the thermodynamic phenomena involved. The aim is to determine how to maximise the energy recovered by the Rankine bottoming cycle.

\subsubsection{Variation in recovered energy}

The first observations are made on the basis of two-dimensional variations $\left(Q_{f}, P_{h p}\right)$ at $P_{l p}=1$ bar.

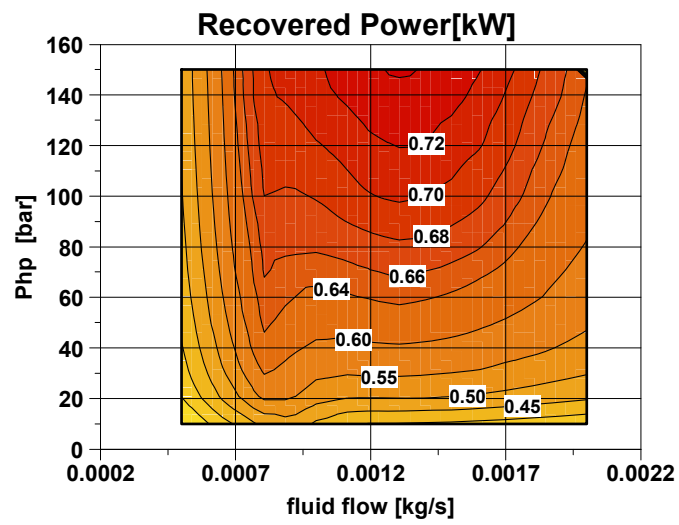

Figure 9: Graph of recovered power on the operating point op\#1. $\mathrm{P}_{\mathrm{lp}}=1$ bar

Whether under the conditions of the operating point at $5 \mathrm{~kW}$ (Figure 9) or at $20 \mathrm{~kW}$ (Figure 10), the energy recovered varies roughly in the same way.

- The pressure $P_{h p}$ in the boiler has a monotonous impact on the energy recovered. The higher the pressure, the greater the energy recovered.

- At fixed pressure, the recovered energy goes through an optimum as a function of the heat exchange fluid flow rate $Q_{f}$.

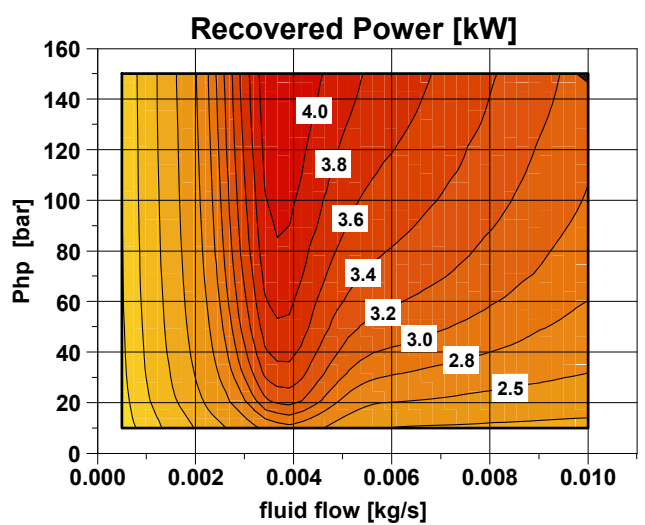

Figure 10: Graph of recovered power on the operating point op\#2. $\mathrm{P}_{\mathrm{lp}}=1$ bar.

Concerning the pressure $P_{l p}$ in the condenser and at machine output, the simulations clearly indicate a minimum value $P_{\min }$ below which the recovered energy decreases (Figure 11). It is the limiting pressure allowing complete liquefaction of the fluid in the condenser. Beyond this value, we observe that the pressure $P_{l p}$ is effectively a second order parameter (Figure 12).

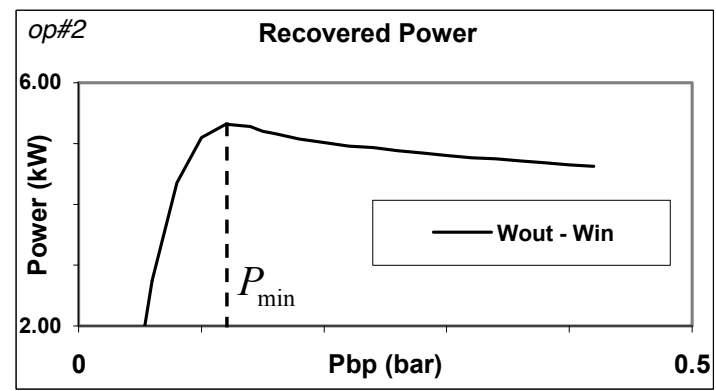

Figure 11: Impact of $\mathrm{P}_{1 \mathrm{p}}$ on the recovered power on operating point op\#2

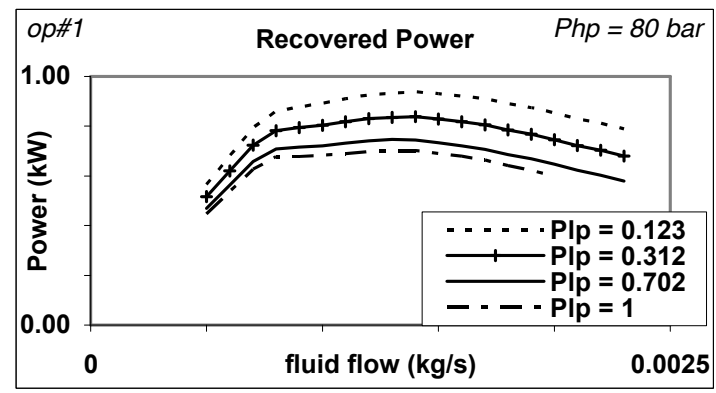

Figure 12: Graph of recovered power against $\mathrm{P}_{\mathrm{lp}}$ on operating point op\#1 


\subsubsection{Variation in efficiencies}

A first level of detail to understand the impact of the parameters on the recovered energy consists in dissociating the variation in efficiencies. Since they are similar for the two operating points, only the simulation results for op\#2 are described in this paragraph (Figure 13).

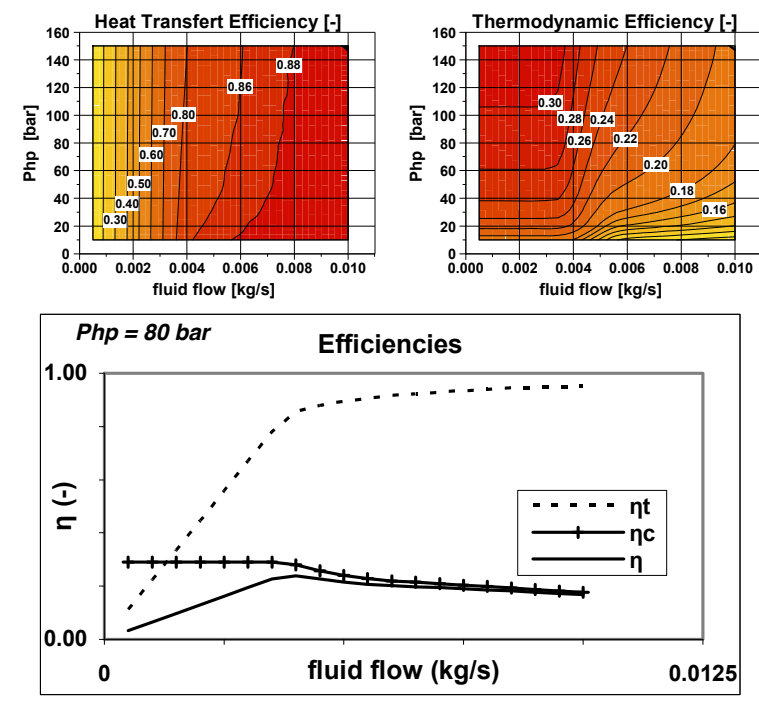

Figure 13: Efficiency variations on operating point op\#2 / detail at $\mathrm{P}_{\mathrm{hp}}=80$ bar

The variation in transfer efficiency depends mainly on the heat exchange fluid flow rate. It is quite surprising, a priori, to see that the pressure $P_{h p}$ has little impact on the efficiency since this pressure controls the fluid evaporation temperature and therefore the temperature difference with the hot source throughout the change of state. The impact of $Q_{f}$ can be explained very simply by considerations on the maximum heat flow transmissible in the exchanger (see 4.4). Also, the transfer efficiency increases as a function of $Q_{f}$ and tends asymptotically to 1 .

The variation in thermodynamic efficiency consists of two separate zones. The first concerns low fluid flow rates for which the thermodynamic conditions at boiler output are constant $\left(Q_{f}<0.003 \mathrm{~kg} / \mathrm{s}\right.$ on Figure 13). The thermodynamic efficiency on this zone depends only on the pressure $P_{h p}$ and corresponds to the variation in energy supplied by an isentropic expansion as a function of the expansion ratio. For higher flow rates, the temperature at boiler output decreases with flow rate $Q_{f}$ and therefore affect the thermodynamic efficiency.

\subsubsection{Exergetic approach}

A second approach to understand the variation in recovered energy consists in observing the similarity with that of the exergy transmitted to the fluid (Figure 14). Based on the description of the notion of exergy given in 3.1, we quickly see that the power produced by the Rankine bottoming cycle is directly related to the exergy transmitted to the heat exchange fluid during the exchange with the hot source.
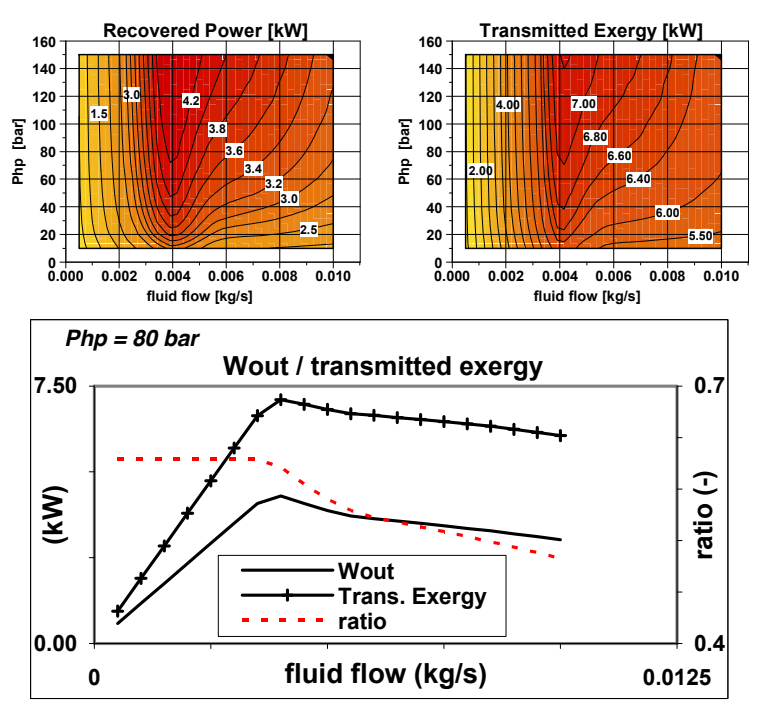

Figure 14: Exergy transmitted to the fluid under operating conditions op\#2

Details of the variation at 80 bar show that if the exergy transmitted to the fluid in the boiler is the first order parameter used to maximise the work recovered, it is not sufficient. The ratio between the exergy transmitted to the fluid and the power supplied by the expander (exergetic conversion efficiency) decreases as soon as the fluid temperature at boiler output decreases. It is therefore important to note that at given pressure $\mathrm{hp}$, there is an optimum fluid flow rate that maximises the work recovered.

\subsection{Setting $Q_{f}$}

In view of the observations made after the first simulations (see paragraph 4.3), we decided to set the fluid flow rate so as to maximise the exergy transmitted. While this does not optimise the energy recovered on all engine operating 
points, it positions this parameter in order to obtain near-maximum efficiency in all cases.

In this context, we can identify a method of determining the exergetically optimum fluid flow rate for a given pressure configuration by studying the heat exchanger behaviour. The approach proposed is based on making the physics of the boiler progressively more complex.

\subsubsection{Exchange with no phase change}

We will first discuss an ideal exchanger, i.e. of infinite area. Initially, ignoring specificities related to the phase change, the behaviour of this type of exchanger is quite simple. It is $100 \%$ efficient and the flow exchanged is limited either by the energy $\Delta H_{e x h}^{\max }$ contained in the exhaust gases or by the energy $\Delta H_{f}^{\max }$ that can be received by the fluid. The two quantities are defined as follows:

$\dot{m}_{f}\left(h_{f}\left(P_{f}, T_{\text {exh }}^{i n}\right)-h_{f}\left(P_{f}, T_{f}^{i n}\right)\right)=\dot{m}_{f} \Delta h_{f}^{\max }=\Delta H_{f}^{\max }$

$\dot{m}_{e x h}\left(h_{e x h}\left(P_{e x h}, T_{e x h}^{i n}\right)-h_{e x h}\left(P_{e x h}, T_{f}^{i n}\right)\right)=\Delta H_{e x h}^{\max }$

With these definitions, the flow of heat transferred from the exhaust gases to the fluid corresponds to the smaller of the two values. Its variation as a function of the fluid flow rate is shown in solid line on Figure 15.

Simplified in this way, the boiler has only two operating modes. For low flow rates, the flow exchanged is limited by the fluid capacity. The fluid leaves the exchanger at the exhaust gas input temperature while some of the heat available is not recovered. This mode is characterised by a constant increase in the exergy transmitted to the fluid as a function of the flow rate. Since the state of the fluid at exchanger output is constant, its specific exergy is also constant. The exergy transmitted therefore increases in proportion to the fluid flow rate. From the equilibrium flow rate $\dot{m}_{0}$, defined by $\Delta H_{f}^{\max }=\Delta H_{e x h}^{\max }$, the energy available in the exhaust gases also becomes limiting. The heat transmitted to the fluid is therefore constant and the exergy decreases naturally, as explained in paragraph 3.1.2.

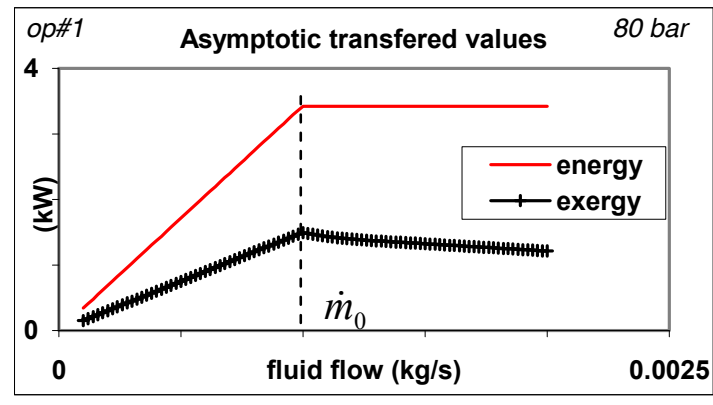

Figure 15: Energy and exergy asymptotic transferred values in the exchanger as a function of the fluid flow rate

Under these simplified conditions, the equilibrium flow rate $\dot{m}_{0}$ corresponds to the fluid flow rate producing maximum exergy transfer for a given fluid pressure.

\subsubsection{Temperature pinch}

Introducing a change of state in the heat exchange process between the exhaust gases and the fluid leads to a special situation concerning the exchanger efficiency. This situation, known as temperature pinch, is illustrated on Figure 16.

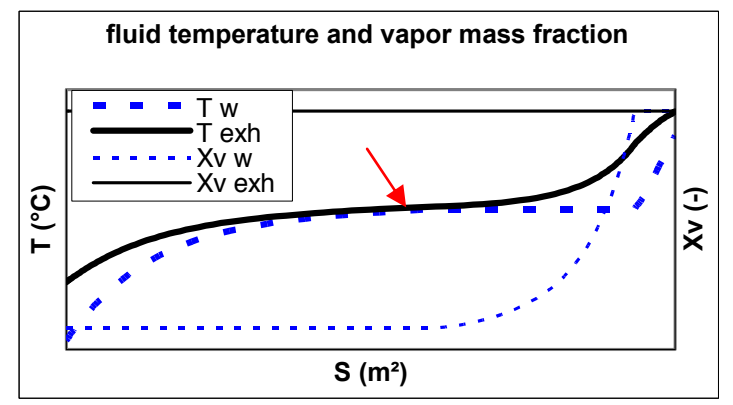

Figure 16: Temperature pinch

In this situation, the transmissible heat flow becomes:

$\Phi^{\max }=\Delta H_{f}^{\text {boil }}+\Delta H_{e x h}^{\text {pinch }}$

where $\Delta H_{f}^{\text {boil }}$ represents the energy required to reach the fluid boiling point $T_{f}^{\text {boil }}$ and $\Delta H_{\text {exh }}^{\text {pinch }}$ represents the amount of energy available in the exhaust between $T_{e x h}^{i n}$ and $T_{f}^{\text {boil }}$.

$\dot{m}_{f}\left(h_{f}^{\text {boil }}\left(P_{f}\right)-h\left(P_{f}, T_{f}^{\text {in }}\right)\right)=\Delta H_{f}^{\text {boil }}$ 


$$
\dot{m}_{\text {exh }}\left(h_{\text {exh }}\left(P_{\text {exh }}, T_{\text {exh }}^{i n}\right)-h_{\text {exh }}\left(P_{\text {exh }}, T_{f}^{b o i l}\right)\right)=\Delta H_{\text {exh }}^{\text {pinch }}
$$

Introducing this phenomenon creates a third operating zone (see Figure 17). In this zone, the temperature pinch causes a reduction in the heat and therefore the exergy transmitted to the fluid. It is bounded on the left by the flow rate $\dot{m}_{1}$ corresponding to the flow rate for which the fluid is just capable of absorbing all of $\Delta H_{e x h}^{p i n h}$ and on the right by $\dot{m}_{2}$, the flow rate for which the energy remaining in the exhaust gases after reaching the fluid boiling conditions is less than $\Delta H_{\text {exh }}^{\text {pinch }}$.

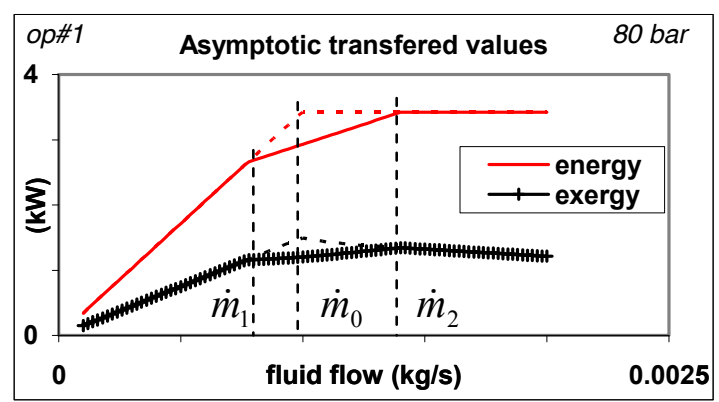

Figure 17: Impact of fluid flow rate on the maximum heat flow

The conditions leading to appearance of pinch depend on the exhaust gas temperature and the fluid pressure in the boiler (see 4.5.2). Under these conditions, the flow rate $\dot{m}_{2}$ corresponds to the upper limit beyond which the exergy transmitted can only decrease. For a boiler of infinite area, therefore, it is also the optimum value of the fluid flow rate as regards the exergy transmitted.

\subsubsection{Taking into account the finite area of the boiler}

The fact that the boiler does not have an infinite exchange area tends to reduce the flow of heat between the exhaust gases and the fluid. This impact increases as the ratio between the thermal power and the exhaust gas input temperature rises. We observe virtually no difference between the asymptotic case and the flow simulated under conditions op\#1 (Figure 18), whereas the effect is much more pronounced with op\#2 (Figure 19).

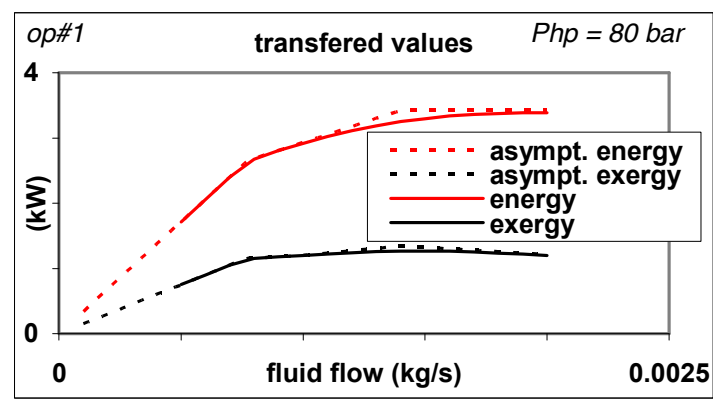

Figure 18: Comparison with the asymptotic case under operating conditions op\#1

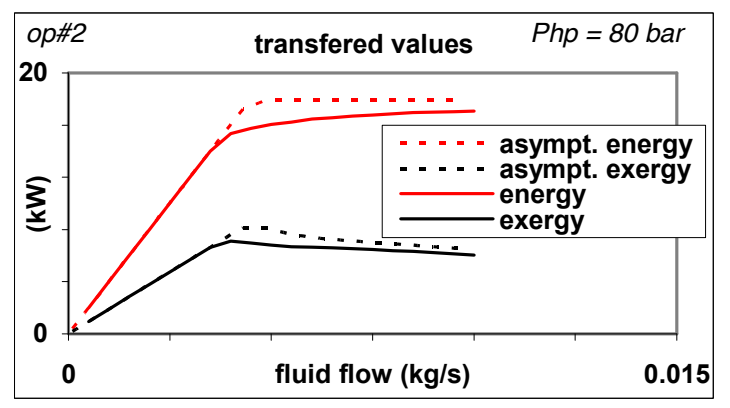

Figure 19: Comparison with the asymptotic case under operating conditions op\#2

In addition, in the pinch temperature situations, limiting the exchange area may be penalising since the exhaust gas temperature is close to the fluid boiling point, which generates low heat flows over a large part of the boiler. In other words, because of temperature pinch the area must be increased to transfer the same amount of heat.

\subsubsection{Choosing the fluid flow rate}

Based on the above analysis concerning operation of the heat exchanger, we can put forward a first approach for the choice of a fluid flow rate suitable for the engine operating conditions and the pressure $P_{h p}$. This approach consists in maximising the exergy transmitted to the fluid while neglecting the variation in exergetic conversion efficiency of the expander.

The method is based on determination of parameters $\dot{m}_{0}, \dot{m}_{1}$ and $\dot{m}_{2}$. It consists in choosing the most favourable flow rate in the asymptotic case, i.e. $\dot{m}_{2}$ in the event of pinch, and $\dot{m}_{0}$ otherwise. Lastly, when the thermal power contained in the exhaust gases increases, the imposed fluid flow rate is equal to $\dot{m}_{1}$ to take 
into account the limitation in flow exchanged by the boiler area. Limitation of the thermal flow between the asymptotic case and the "real" case results in fact in a lower optimum flow rate.

Consequently, this method cannot be used to determine the absolute maximum of recovered energy but guarantees a fluid flow rate which is well positioned in terms of transmitted exergy, since it lies between $\dot{m}_{1}$ and $\dot{m}_{2}$.

\subsection{Setting $P_{h p}$}

In view of the observations made in paragraph 4.3.2, increasing the pressure $P_{h p}$ has little impact on the thermal energy transferred but improves the cycle efficiency (Figure 20).

\subsubsection{Influence on thermodynamic efficiency}

Increasing the pressure in the high pressure circuit increases the thermodynamic efficiency of the Rankine bottoming cycle. This results follows on quite naturally from the study of the theoretical cycle. Without taking the trouble to demonstrate it again, we can nevertheless see that it is true by observing that an increase in $P_{h p}$ increases the boiling point of the heat exchange fluid. This brings us close to the Carnot cycle on the T-S diagram of Figure 3.

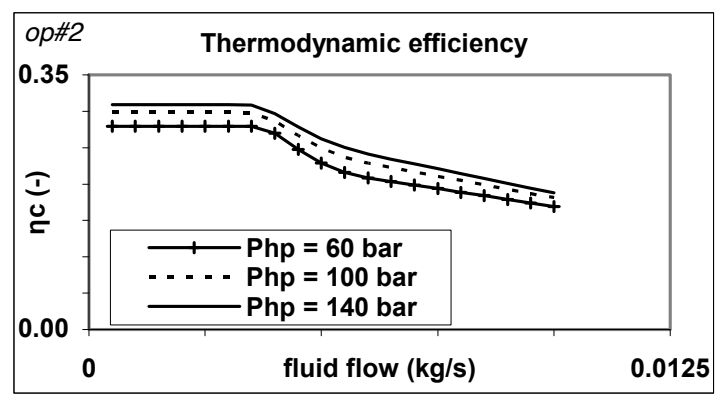

Figure 20: Graph of cycle efficiency against pressure $\mathrm{P}_{\mathrm{hp}}$

From an exergetic point of view, this influence can be accounted for by the fact that there is less exergy destruction in the boiler. Increasing the pressure $P_{h p}$ raises the fluid boiling point $T_{f}^{b o i l}$, in fact. During the fluid boiling phase therefore, there is less difference between the temperatures of the fluid and the hot source.
However, the irreversibilities and therefore the exergy destruction during the heat transfers increase with the temperature difference.

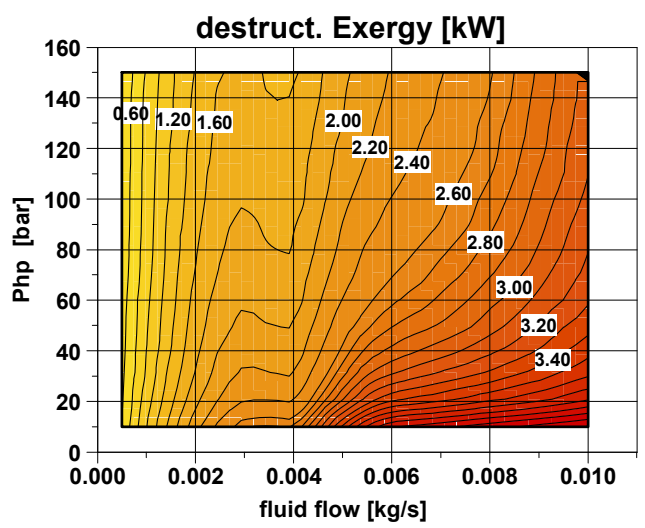

Figure 21: Exergy destruction in the boiler (operating conditions op\#2)

\subsubsection{Influence on pinching}

The pressure in the boiler also has an impact on the appearance of temperature pinch situations and on the corresponding flow rates $\dot{m}_{1}$ and $\dot{m}_{2}$. We demonstrate that above a certain temperature of the hot source, there is a fluid pressure beyond which pinching is impossible. For example, under conditions at the exhaust of engine operating point op\#2 $\left(T_{e x h}^{i n}=790{ }^{\circ} \mathrm{C}\right)$, pinching becomes theoretically impossible if the water pressure is greater than 180 bar. The right hand graph of Figure 22 shows that the flow rates $\dot{m}_{0}$, $\dot{m}_{1}$ and $\dot{m}_{2}$ are equal when $P_{h p}$ is equal to 180 bar. Pinching cannot be avoided, however, under the conditions of operating point op\#1 $\left(T_{e x h}^{\text {in }}=550\right.$ ${ }^{\circ} \mathrm{C}$ ).
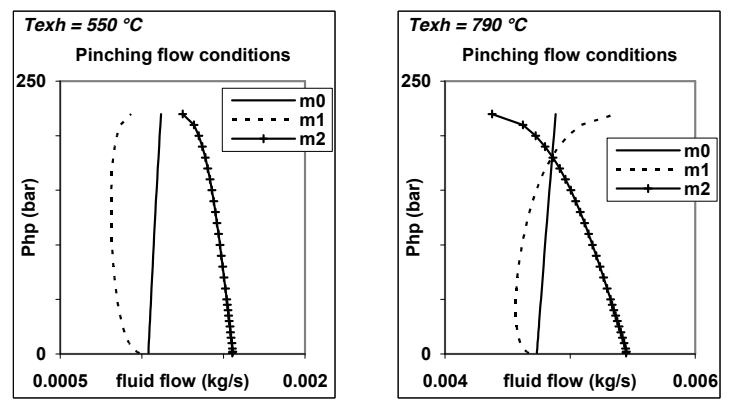

Figure 22: Influence of $\mathrm{P}_{\mathrm{hp}}$ on the pinching conditions for two hot source temperatures. 
Consequently, increasing the pressure in the high pressure circuit pushes back the pinching situations. Since these situations are penalising from the point of view of transferable exergy with a boiler of finite area (4.5.3), this is an interesting property.

\subsubsection{Choosing $P_{h p}$}

In view of the impact on the cycle efficiency and the pinching conditions, the pressure $P_{h p}$ required simply corresponds to the maximum pressure permissible in the circuit. We must nevertheless bear in mind that increasing this pressure setpoint has an impact on the transmissible heat flow in the boiler due to its exchange area. The exchange area must therefore be increased when considering high pressures. Given the temperatures measured at catalyst outlet on a spark ignition engine, however, this constraint only appears for low thermal powers at the exhaust. In this case, the boiler area often proves sufficient since it is designed for much higher pressures.

\subsection{Setting $P_{l p}$}

The pressure in the condenser determines the liquefaction temperature $T_{f}^{\text {liq }}$ of the heat exchange fluid. However, the heat exchange fluid must be fully condensed at exchanger output. Much more energy is in fact required to compress a gas than a liquid. The aim is to limit excessive cooling of the fluid beyond liquefaction since the heat transmitted to the cold source is lost from the energy recovery point of view.

\subsubsection{Condenser operation}

Via the fluid liquefaction temperature, the pressure in the condenser determines the temperature difference between fluid and cold source and therefore the quantity of energy which can be evacuated in the condenser.

The liquefaction constraint imposes a minimum pressure in the condenser (Figure 23). This value corresponds to the fluid pressure generating a liquefaction temperature such that the temperature difference between the fluid and the cold source is sufficient to dissipate the energy required to liquefy the fluid, given the exchange area available in the condenser.

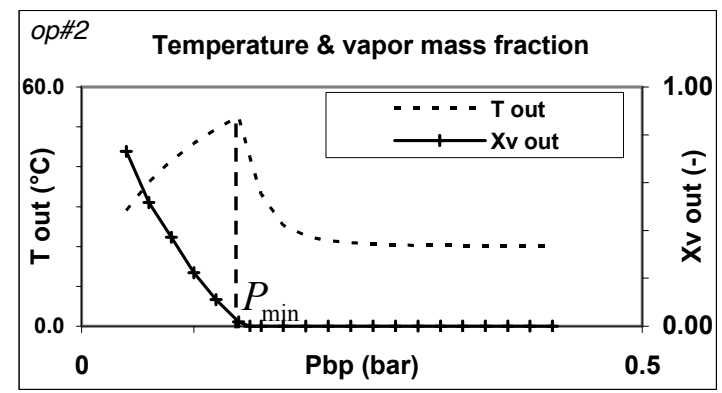

Figure 23: Graph of fluid state at condenser output against $\mathrm{P}_{\mathrm{lp}}$

We see in fact that this minimum pressure corresponds to the maximum recovered energy shown on the graph of Figure 11. To determine $P_{\min }$, we must solve the following implicit equation:

$\dot{m}_{f}\left(h_{f}^{i n}-h_{f}^{l i q}\left(P_{l p}\right)\right)=\Phi\left(S, P_{l p}, \dot{m}_{f}, T_{f}^{i n}, T_{\text {cold }}\right)$

We must determine the pressure $P_{l p}$ such that the power $\Phi$ that can be evacuated by the condenser is equal to the enthalpy difference required to liquefy the fluid without cooling it any further. This power also depends on the exchanger area $S$, the fluid input temperature $T_{f}^{i n}$ and the cold source temperature $T_{\text {cold }}$.

In practice, the system is necessarily a closed loop since $P_{l p}$ has an influence of the work supplied to the expander and therefore on the fluid enthalpy level $h_{f}^{\text {in }}$ at condenser inlet.

\subsubsection{Influence on cycle efficiency}

As for $P_{h p}$, the pressure $P_{l p}$ at expander outlet has an impact on the thermodynamic efficiency. Lowering the pressure lowers the liquefaction temperature of the heat exchange fluid. This allows us to increase the area of the cycle from the bottom in the T-S diagram. In other words, the work supplied by isentropic expansion is increased by increasing the expansion rate.

\subsubsection{Choosing $P_{l p}$}

In view of the previous explanations, the optimum pressure imposed in the boiler is equal to $P_{\min }$. In practice, a margin of $5 \mathrm{mbar}$ is applied in order to allow for certain approximations 
made when calculating the flow that can be evacuated by the condenser.

\section{Applications}

By applying the setpoints developed in the previous paragraphs, we can compare other configurations without using three-dimensional sweeps to determine the useful values of the setting parameters.

This paragraph therefore describes a recoverable energy balance for the entire engine map and the evaluation of two technological modifications:

- $\quad$ presence of a system to preheat the fluid using the engine cooling water

- impact of the type of the working fluid

\subsection{Potential in steady state run}

By applying these setpoints to all engine operating points we can determine, to an order of magnitude, an image of the recoverable energy potential in steady state run.

Since the optimum setting of $P_{h p}$ consists in reaching the maximum value, we decided to simulate all engine map points for a pressure of 120 bar. This value corresponds to a limit considered as acceptable in view of the existing studies ([6], [11] and [14]).

\subsubsection{Relevance of the settings}

We must first check that the settings proposed are relevant, on the two engine operating points studied so far. The optimum values resulting from three-dimensional variations of the setting parameters are compared with the results obtained by simply applying the setpoints proposed in paragraph 4. This comparison is summarised in Table 3.

Table 3: Relevance of the settings proposed

\begin{tabular}{|l|c|c|c|c|}
\hline & \multicolumn{2}{|c|}{ op\#1 } & \multicolumn{2}{c|}{ op\#2 } \\
\hline & prop. & opti. & prop. & opti. \\
\hline Qf (kg/s) & 0.0013 & 0.0015 & 0.0047 & 0.004 \\
\hline Php (bar) & 120 & 120 & 120 & 120 \\
\hline Plp (bar) & 0.041 & 0.041 & 0.145 & 0.134 \\
\hline Qin (kW) & 3.22 & 3.29 & 15.24 & 14.84 \\
\hline Win (kW) & 0.02 & 0.02 & 0.07 & 0.06 \\
\hline Wout (kW) & 1.05 & 1.06 & 5.30 & 5.46 \\
\hline
\end{tabular}

This comparison is satisfactory since, out of the two operating points tested, there is no major difference between the optimum settings and those proposed by the method described in paragraph 4 .

\subsubsection{Recovered power}

Given the assumptions made on the expander (4.2.1), it is highly likely that the recoverable energy balance over the entire cartography has been overestimated. The values shown on Figure 24 must therefore be considered as an upper limit.

Reduced to the exergy initially available in the exhaust gases, this balance reveals a fairly large variation between the operating points (Figure 25). This is due to the fact that the boiler, designed for operating point op\#2, is not adapted to higher powers. In addition, since the temperature of the hot source increases with the power of the thermal engine, exergy destruction in the boiler increases due to the difference in temperature with the fluid boiling point.

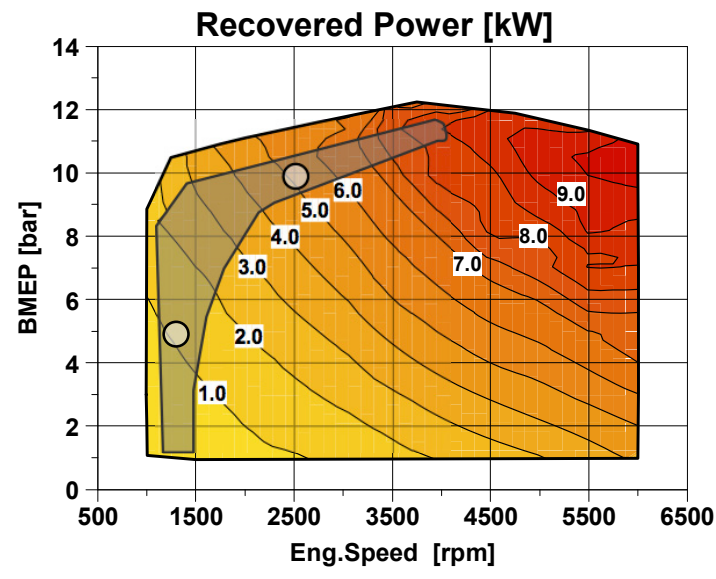

Figure 24: Recovered energy over the entire map

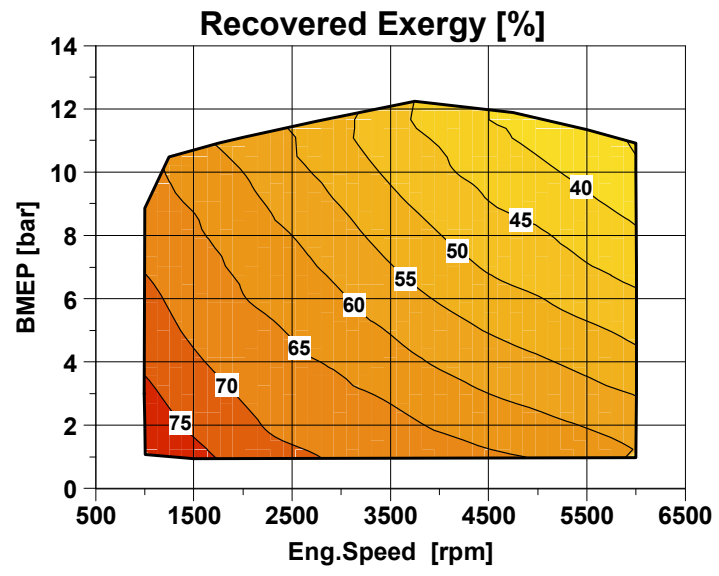

Figure 25: Recovered exergy fraction 


\subsubsection{Fluid mass variation}

The cartographies shown in the previous paragraph were built using optimum results according to the methods defined previously. Parameters $P_{h p}, P_{l p}$ and $Q_{f}$ are set independently for each operating point. We observe that this point by point optimisation leads to a significant variation in the total mass of fluid in the system. Figure 26 gives an estimation of the variation in total mass of water in the circuit compared with the median value.

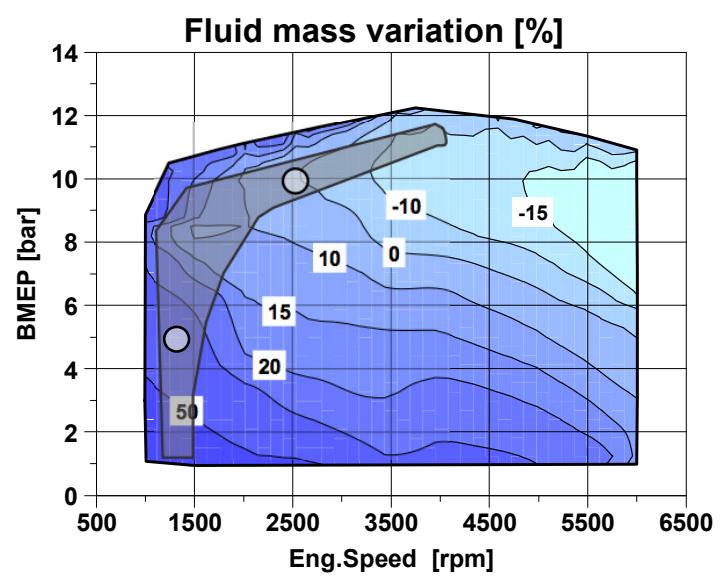

Figure 26: Heat exchange fluid mass variation

The fluid mass enclosed in the Rankine system changes due to the variability of the density profile within the heat exchangers. Depending on the phase change profiles in the boiler and the condenser, the fluid in liquid state takes up more or less space.

In view of this observation, we must include a system allowing the enclosed fluid mass to vary so that this parameter does not limit the cycle recovery efficiency. The system consists of a tank connected to the circuit each side of the pump via control valves (Vhp and Vlp on the diagram of Figure 27).

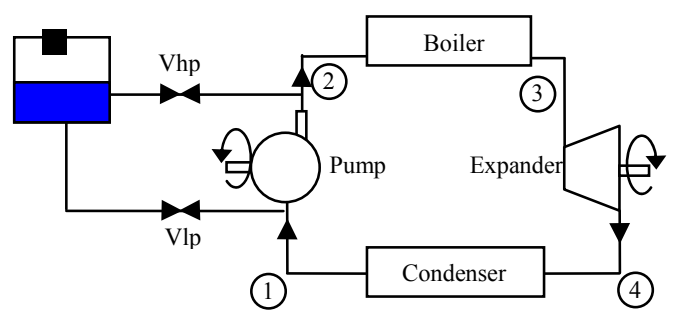

Figure 27: Diagram of a fluid mass control system
This type of system offers a simple means of controlling the enclosed fluid mass and acts as a third actuator thereby allowing optimum control of the cycle. The Rankine bottoming cycle is in fact controlled by three parameters $\left(Q_{f}, P_{h p}\right.$ and $P_{l p}$ ) whereas, in its simplest version (Figure 8), the system only has two actuators:

- the pump volumic flow rate

- the expander volumic flow rate

The fluid mass is controlled by opening Vhp to remove mass from the circuit and by opening Vlp to add mass to the circuit. The tank calibration pressure must lie between the variation ranges of $P_{h p}$ and $P_{l p}$.

\subsection{Influence of the heat exchange fluid}

\subsubsection{Fluid flow rate}

The thermodynamic properties (specific heat capacity and latent heat of vaporisation) of organic fluids are lower than those of water. Greater flow rates are therefore required if they are to be used to recover energy at the exhaust. Consequently, the boiler must be specifically designed and provide a larger exchange area.

\subsubsection{Adaptation with respect to the hot source temperature}

We have already seen that the difference in temperatures between the hot source and the fluid in the boiler was responsible for exergy destruction. It therefore seems obvious that a suitable fluid will have a boiling curve that approaches the temperature of the hot source during the heat transfer phase. The graph of Figure 28 shows the situation of the phase change curves of the fluids tested with respect to the temperature of the exhaust gases. Water is clearly the best liquid. 


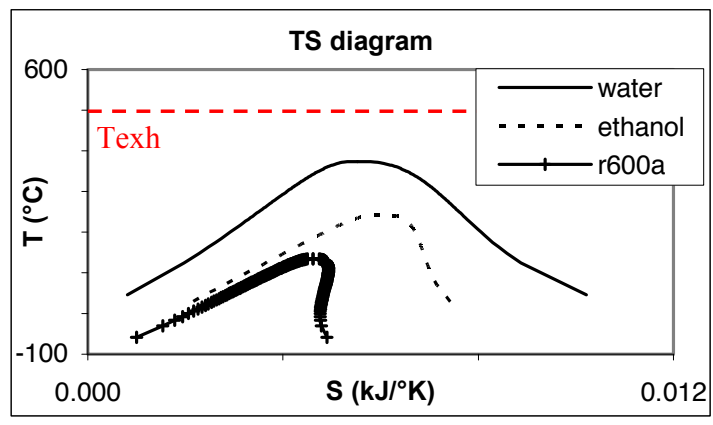

Figure 28: Proximity of the phase change curves with the temperature of the hot source

\subsubsection{Simulation results}

The simulations used to compare the potential of the heat exchange fluids were carried out on operating point op\#1. Under these conditions, in view of the temperature pinch effect in the boiler, it may be worthwhile choosing an organic fluid. In addition, in order to compare the various fluids under the same conditions, we decided to set the pressure in the boiler to the critical pressure $P_{\text {crit }}$ of the fluid considered. This allows to compare the maximum potential of each configuration. The results obtained are given in Table 4.

Table 4: Heat exchange fluid variation, main results for $\mathrm{P}_{\mathrm{hp}}=\mathrm{P}_{\text {crit }}$

\begin{tabular}{|l|c|c|c|}
\hline & \multicolumn{3}{|c|}{ op\#1 } \\
\hline Fluid & water & ethanol & R600a \\
\hline Qf (kg/s) & $1.25 E-03$ & $1.73 E-03$ & $5.07 \mathrm{E}-03$ \\
\hline Php (bar) & 220 & 61 & 36 \\
\hline Plp (bar) & 0.04 & 0.10 & 3.98 \\
\hline Qin (kW) & 3.11 & 3.22 & 3.40 \\
\hline Win (kW) & 0.03 & 0.02 & 0.03 \\
\hline Wout (kW) & 1.10 & 0.99 & 0.53 \\
\hline
\end{tabular}

These results confirm that water is the best choice for an application at the exhaust of spark ignition engines. It must nevertheless be possible to meet the technological constraints related to the required pressure level, even if the example presented here is an extreme case since it corresponds to the critical pressure of the fluid.

\subsection{Preheating using the cooling water}

A more sophisticated alternative to the recovery of thermal energy from the exhaust gases alone consists in preheating the fluid in contact with the coolant before sending it into the boiler. With this method, we hope to recover some of the heat present in the cooling water. Figure 29 is a simplified diagram of this type of system.

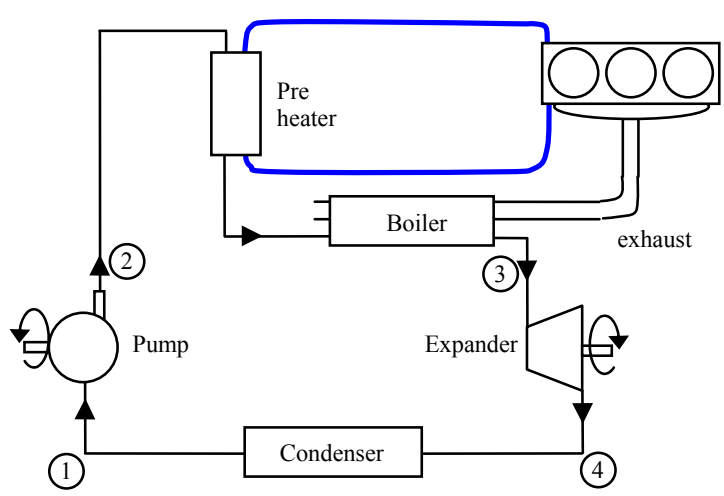

Figure 29: Diagram of fluid preheated by cooling water

\subsubsection{Comparisons}

For this type of system, the energy transferred from the cooling circuit to the heat exchange fluid is necessarily low. Given the difference between the latent heat of vaporisation and the specific heat capacity of the fluids, the quantity of energy that can be absorbed by the fluid during preheating is between $10 \%$ and $20 \%$ of the energy required for complete vaporisation. For a system using water as heat exchange fluid, however, vaporisation can only occur in contact with the exhaust gases.

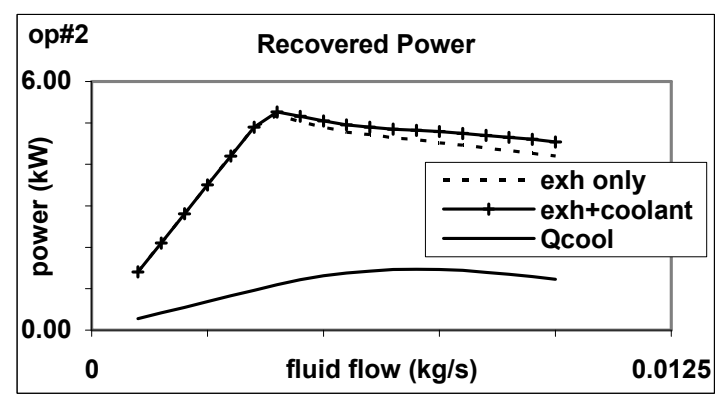

Figure 30: Energy recovered with and without preheating

The simulation results also demonstrate that the energy introduced during preheating is not used very efficiently by the expander. This is due to the fact that the fluid flow rate corresponding to the maximum energy recovered is that for which the heat exchange fluid absorbs a maximum amount of the heat energy from the exhaust gases while remaining at high temperature at boiler outlet. There is therefore no point in preheating the fluid since the energy recovered during the preheating phase replaces some of the energy 
which could have been recovered in the exhaust gases.

\section{Conclusions and future studies}

\subsection{Analyses and settings}

Construction of a simulation tool provided us with further knowledge about the phenomena involved in the efficiency of an energy recovery system using a Rankine bottoming cycle. Their simple modelling led to a first method for setting the control parameters. This method ensures a good level of recovery based on physical considerations alone. If a demonstrator should be developed, they could act as a basis to control the system.

While the methods proposed to set $P_{h p}$ and $P_{l p}$ are satisfactory since optimum, further studies must be conducted to improve the determination of fluid flow rate. These studies focus on two aspects :

- modelling and taking into account the attenuation of the heat flow transmitted in the boiler, related to the exchanger area.

- modelling and taking into account the exergy conversion efficiency response of the expander.

\subsection{Simulation tools}

By transposing the models used for this study under the simulation software AMESim, it should be possible to improve the understanding and evaluation of the energy recovery cycle using the Rankine bottoming cycle.

In particular, it should allow us to study the transient aspects and measure the impact of the heat exchange dynamics on the energy finally recovered during a driving cycle. Considering the importance of the thermal inertia, adopting a quasi static approach for this exercise is quite unrealistic. With AMESim, it will also be easier to implement expander models. To compare different fluids, for example, this aspect becomes blocking.

Lastly, construction of a dynamic simulator using AMESim is an important step in the development of control laws.

\subsection{Experimental studies}

Creation of a first recovery system on test bench at IFP will allow an initial confrontation with the physical reality of the system. This system will run on water and produce electrical energy. Most of the current simulation studies are therefore conducted with this project in mind.

\section{Abbreviations}

$Q_{\text {in }} \quad$ thermal power exchanged with the hot source

$Q_{\text {out }} \quad$ thermal power exchanged with the cold source

$W_{\text {in }} \quad$ mechanical power supplied to the compressor

$W_{\text {out }} \quad$ mechanical power supplied by the expander

$Q_{f} \quad$ mass flow rate of the heat exchange fluid

$P_{h p} \quad$ pressure in the high pressure circuit

$P_{l p} \quad$ pressure in the low pressure circuit

$\dot{m}_{a} \quad$ mass flow rate of "a" $(\mathrm{kg} / \mathrm{s})$

$h_{a}(P, T)$ specific enthalpy of the species "a" under pressure and temperature conditions $\mathrm{P}$ and $\mathrm{T}$

$h_{a}^{\text {boil }}(P) \quad$ specific enthalpy at the boiling point of fluid "a" at pressure $P(\mathrm{~J} / \mathrm{kg})$

$\eta_{t} \quad$ energy transfer efficiency

$\eta_{c} \quad$ thermodynamic efficiency

$\eta \quad$ global efficiency

$E_{\text {exh }} \quad$ energy flow in the exhaust

$E_{w} \quad$ energy flow in the cooling water

$S_{a}(P, T)$ entropy of the species "a" under pressure and temperature conditions $\mathrm{P}$ and $\mathrm{T}$

LHV lower heating value

\section{References}

[1] Guillaume Bourhis, Pierre Leduc, IFP, Energy and Exergy Balances for Modern Diesel and Gasoline Engines, Les rencontres scientifiques de l'IFP - Advances in Hybrid Powertrains, 2008

[2] Koichiro Muta, Makoto Yamazaki and Junji Tokieda, Toyota Motor Corp., Development of New-Generation Hybrid System THS II Drastic Improvement of Power Performance and Fuel Economy, SAE Technical Paper 2004-01-0064, 2004 
[3] Peter Feulner, Ricardo GMBH, Additional Energy Converters in Future Vehicles, MTZ 09|2008 Volume 69

[4] Ove B. Platell, Progress of Saab Scania's Steam power Project, SAE Technical Paper 760344

[5] MAN B\&W Diesel A/S Thermo Efficiency System (TES) for Reduction of Fuel Consumption and CO2 Emission

[6] Prof. Dr.-Ing. Raymond Freymann, The turbosteamer - A system introducing the Principle of Cogeneration in Automotive Applications, MTZ05|2008 Volume 69

[7] Rody El Chammas, Denis Clodic, Center for Energy Studies, Ecole des Mines de Paris, Combined Cycles for Hybrid Vehicles, SAE 2005-01-1171, 2005

[8] J.B. Heywood, Internal Combustion Engine Fundamentals, 1988

[9] Eur Ing J A McGovern, Exergy analysis - a different perspective on energy - Part 1 : the concept of exergy, SAE Technical Paper 904793, 1990

[10] Eur Ing J A McGovern, Exergy analysis - a different perspective on energy - Part 2 : rational efficiency and some examples of exergy analysis, SAE Technical Paper 904794, 1990

[11] T. Endo and al., Honda R\&D Co, Study on Maximizing Exergy in Automotive Engines, SAE Technical Paper 2007-01-0257, 2007

[12] Kakac Sadik, Liu Hongtan, Heat exchangers : selection, Rating, and thermal Design, Second Edition, London : CRC press, 2002

[13] Franck P. Incropera, David P. DeWitt, Introduction to Heat Transfert, Fourth Edition, Wiley 2002

[14] Kensaku Yamamoto, Advanced Hybrid Vehicle Using Rankin Cycle System, Honda R\&D Co, 2008

\section{Authors}

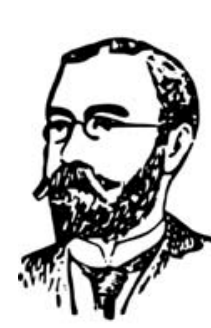

Alexandre Duparchy is a research engineer in the IFP Engine Technology Department. He holds an engineering diploma from the Ecole Nationale Supérieur de l'Aéronautique et de l'Espace, an engineering diploma from the Ecole Nationale Supérieure du Pétrole et des Moteurs and a DEA in fluid dynamics 